\title{
Design of a 1KVA Solar Inverter System.
}

\author{
Engr C.O Ezeagwu, Agugua Chukwunenye I, Udoh Chinedu C, Oluchi Nwafor C. \\ Department of Electronics and Computer Engineering, \\ Nnamdi Azikiwe University.
}

DOI: 10.31364/SCIRJ/v7.i10.2019.P1019709

http://dx.doi.org/10.31364/SCIRJ/v7.i10.2019.P1019709

\begin{abstract}
This project is concerned with the design, analysis and construction of a solar conversion system which consist of a solar panel an inverter and a battery. The solar panel traps the sunlight and converts it into direct current which is used to charge the battery through the charging circuit. The inverter converts the direct current power into alternating current power. The battery is being charged from either solar panel or power mains. The components that make up the system and their arrangement into sections or circuits are discussed. A test was done to ascertain its effectiveness. A solar conversion system is recommended to be used in homes, offices and industries. It is very expensive but it is hoped that the cost will reduce owing to the on-going research in the field.
\end{abstract}

Index Terms - solar inverter system, electricity, solar system

\section{Introduction}

Electricity is the most versatile and generally accepted useful Energy available in the modern world today. Electrical energy therefore is of paramount importance for the industrialization of any nation. The use of electricity has gradually increased over the years. It now contributes about $60 \%$ of the total energy used in the whole world. Electricity used for illuminations, heating, industrial electric motors, machines, railway tractors etc. has been extended to literally every sector of the economy particularly for commercial and domestic use. The adequate generation of electric power, the stability and efficiency of a power system give great strength to industries, thus, improving the economy of the nation. The standard of living of a nation is improved due to the availability of new jobs for the youths. Hence electrical energy generation and efficient delivery will continue to be of fundamental importance to the technological advancement of any nation including Nigeria (Abdullahi Babatunde Saka et al) [1].

Due to erractic supply of electricity to residential buildings made most occupants/owners to source for alternative sources to compliment epileptic supply from national grid. Assessing the level of awareness, adoption and barriers as related to solar PV system in cities in Nigeria, large percentage of the residential buildings make use of diesel/petrol generating set as an alternative to the national grid, the level of awareness if solar PV is significantly low (Saka Abdullahi et al) [1].

The First-generation solar cells ( Mono-crystalline cell, Poly-crystalline cell and Ribbon silicon) dominate the market with their low costs and the best commercially available efficiency. They have a relatively mature PV technology, with a wide range of well established manufacturers. The Second-generation(Amorphous Silicon, Cadmium-Telluride, Copper-Indium Selenide); Thin film PV technologies are attractive because of their low material and manufacturing costs. They are less mature than first generation PV and still have a modest market share. The Third-generation technologies are yet to be commercialized at any scale (Wikipedia) [2].

The solar system consists of $\mathbf{4 0}$ spaced solar cells made Copper Indium Gallium Selenide Solar Cells (CIGS) and of cylindrical shapes. Due to its open design, the solar system allows the solar cells cooling by natural ventilation. The measurement is taken for a horizontal $\left(\mathbf{0}^{\circ}\right)$ and inclined panel $\left(\mathbf{3 0}^{\circ}\right)$, and for a gray and white soil. When experinmented results showed the advantage of the inclined system collects higher intensity of the solar radiation, resulting the higher electrical production of pv panel. A higher electrical production will be obtained for the white soil which, unlike the gray one, allows the panel to operate with an additional part 
of the solar radiation which is that reflected by this soil. A 3D CFD model interpreting this solar system's operating was then developed and simulation results showed a good agreement with the experimental data (Wael Charfi et al 2018) [3]. This report documents the design of an inverter. The various applications of the inverter are Wind/solar electrical systems, Back-up for power cells, Generator support systems, Remote homes, Telecommunications, Computers, Tools, Security applications, Mobile power, Boats and yachts, Airplane, Monitoring equipment, Emergency power and lighting etc.

\section{Method}

\subsection{Power Supply and Transformer Selection}

A transformer is an electrical device that is used to transfer electrical energy from one circuit to another through electromagnetic induction without changing the frequency of the electric energy. With an alternating current, a transformer will either step up or step down the voltage as it makes the transfer. In power conversion application of an inverter, the power transformer plays a major rule. It is usually design and constructs to step up a low voltage input to 220 to 240volts. This unit of the system is responsible for powering the entire system. The input voltage of the system is $24 \mathrm{~V}$, a voltage regulator was used to regulate the $24 \mathrm{~V}$ input into $12 \mathrm{~V}$ and $5 \mathrm{~V}$.

\subsection{Design and Selection of Solar Battery Used}

In this case, a $12 \mathrm{~V} \mathrm{DC}, 75 \mathrm{AH}$ battery was used as energy storage for the solar inverter. The voltage capacity of the battery can be obtained from the following relationship:-

Power available in watt-hour $=($ battery size in $\mathrm{AH}) \times($ battery voltage in volts $)$

Mathematically, power available in watt-hour

$=75 \mathrm{AH} \times 12$ volts $=900$ watt-hour

This implies that, the battery could supply 900 watts for 1hour, 450 watts for 2 hours and so on. Thus the more load the faster the battery discharges

\subsection{Oscillator Circuit Design Stage}

An IC SG3524 is use to generate the necessary pulse needed to drive the MOSFET (IRF140) to alternate the DC supply. The output from the oscillator stage is amplified using transistor (BC557). This amplified signal triggers the metal-oxide field-effect transistor with Vgs (gate to source voltage) greater than threshold voltage. 
Fig 1.0

Schematic

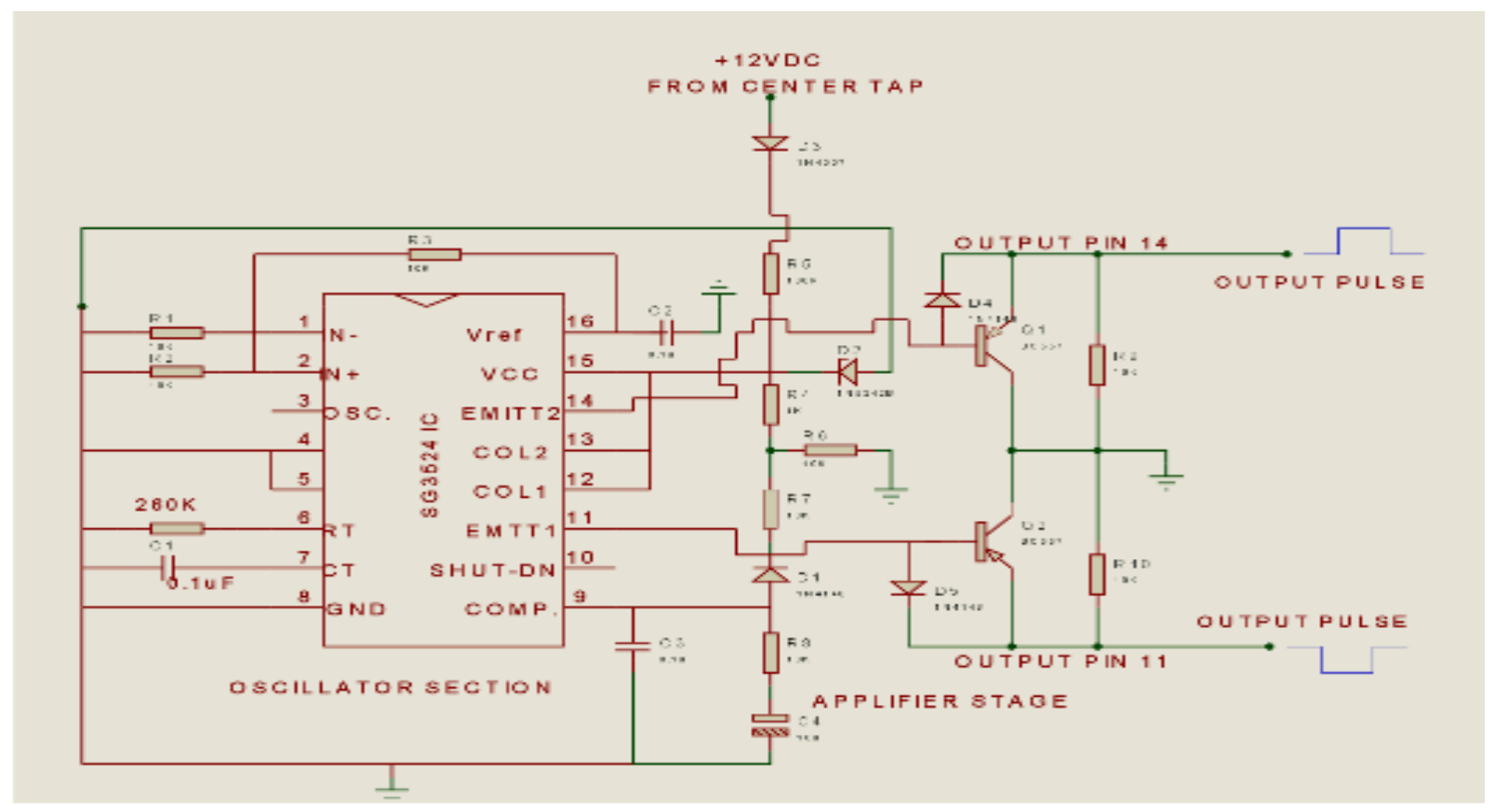

Diagram of Oscillator/Driver Circuit.

\subsection{Design of Driver Circuit}

The drive circuit is not more than bipolar junction transistors (BJTS) and resistors connected in such fashion as to amplify the weak drive signals from the output pin11 and pin 14 of the pulse generator circuit to the level required by the power switches (NMOS). It also provides electrical isolation when required between the power switch and the logic level signal processing circuit (pulse generator).

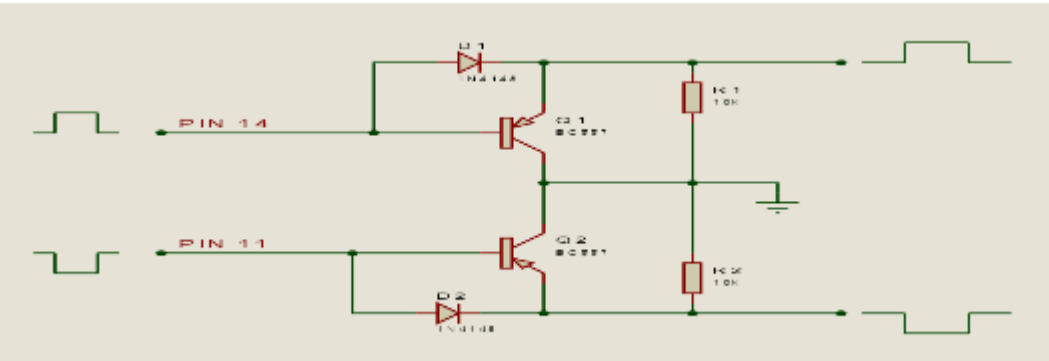

Fig 2 Schematic Diagram of Driver/Oscillator Circuit.

\subsection{Design of the External Feedback Circuit For (PWM)}

The feedback circuit order wise known as pulse width modulator or adjuster. It is an external circuit that comprises of series and shunt resistor together with rectifier circuit. It is designed in such a way to keep the system output voltage stable or balanced and also used to set the output voltage of inverter to 220volt or 230volt, $50 \mathrm{~Hz}$. 


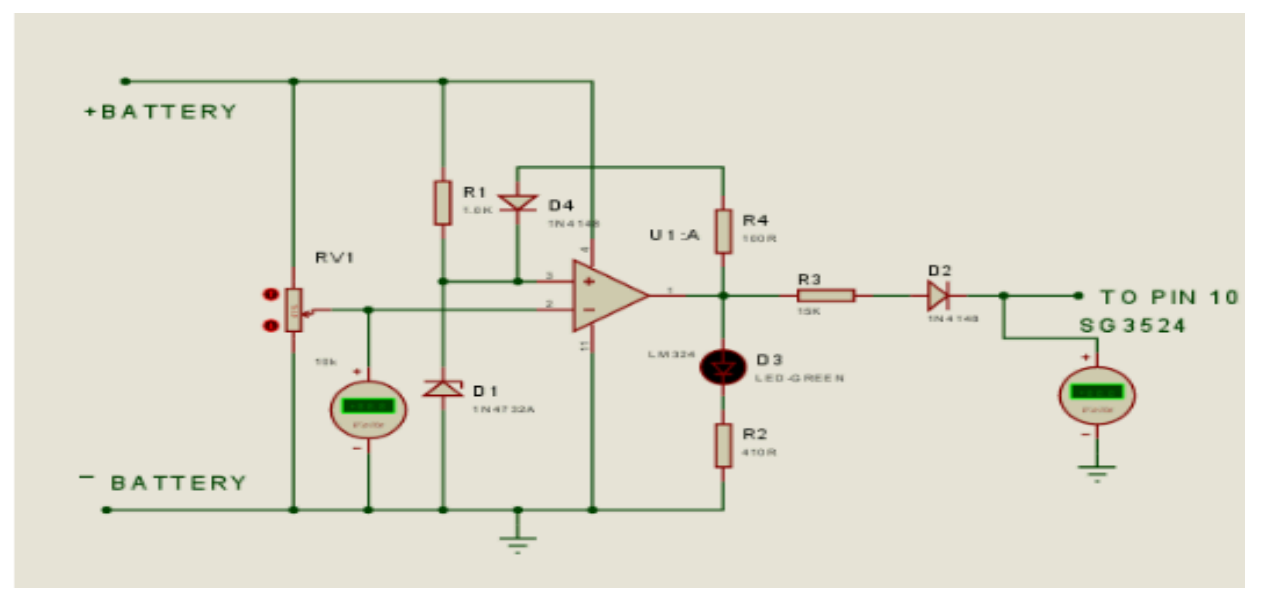

Fig 3 Feedback Circuit (Pulse Width Adjuster) Diagram.

\subsection{Extra Protection Circuit Design}

The external protection circuit are incorporated into this design to protect the inverter against excessive draining of battery voltage when in operation and also from overloading. This is because the inverter will be seeing the loads as short circuit current that can cause damages in the power MOSFETs used. The extra protective circuits used in the design are:

i. Low battery shutdown circuit.

ii. Overload protection circuit.

The circuit of auto shutdown is shown below. It comprises of single comparator few external components as shown below

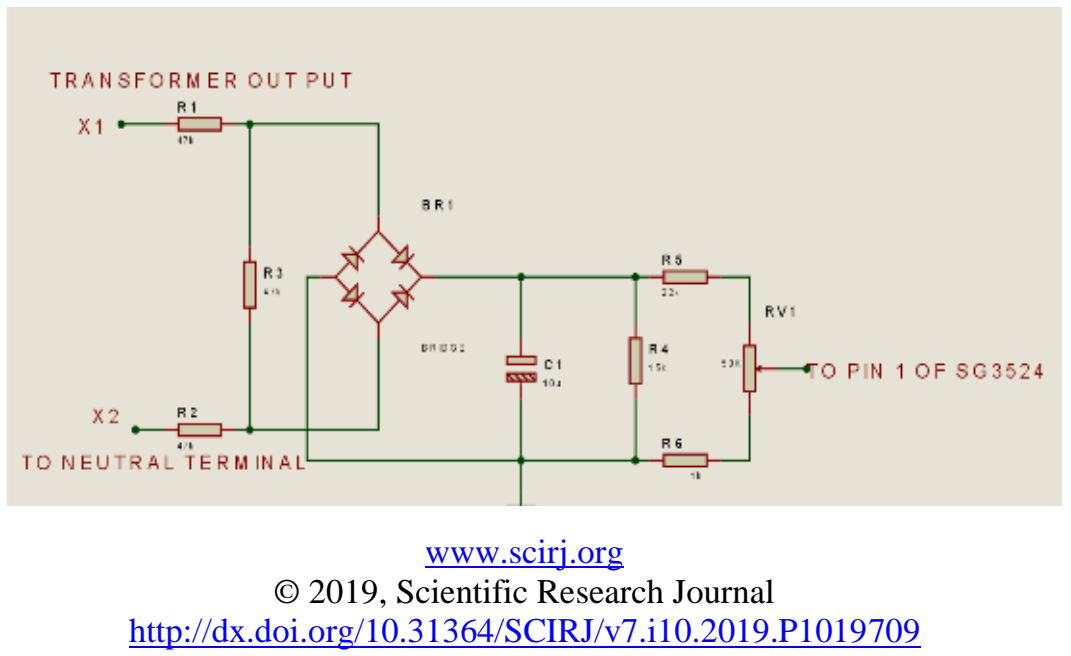




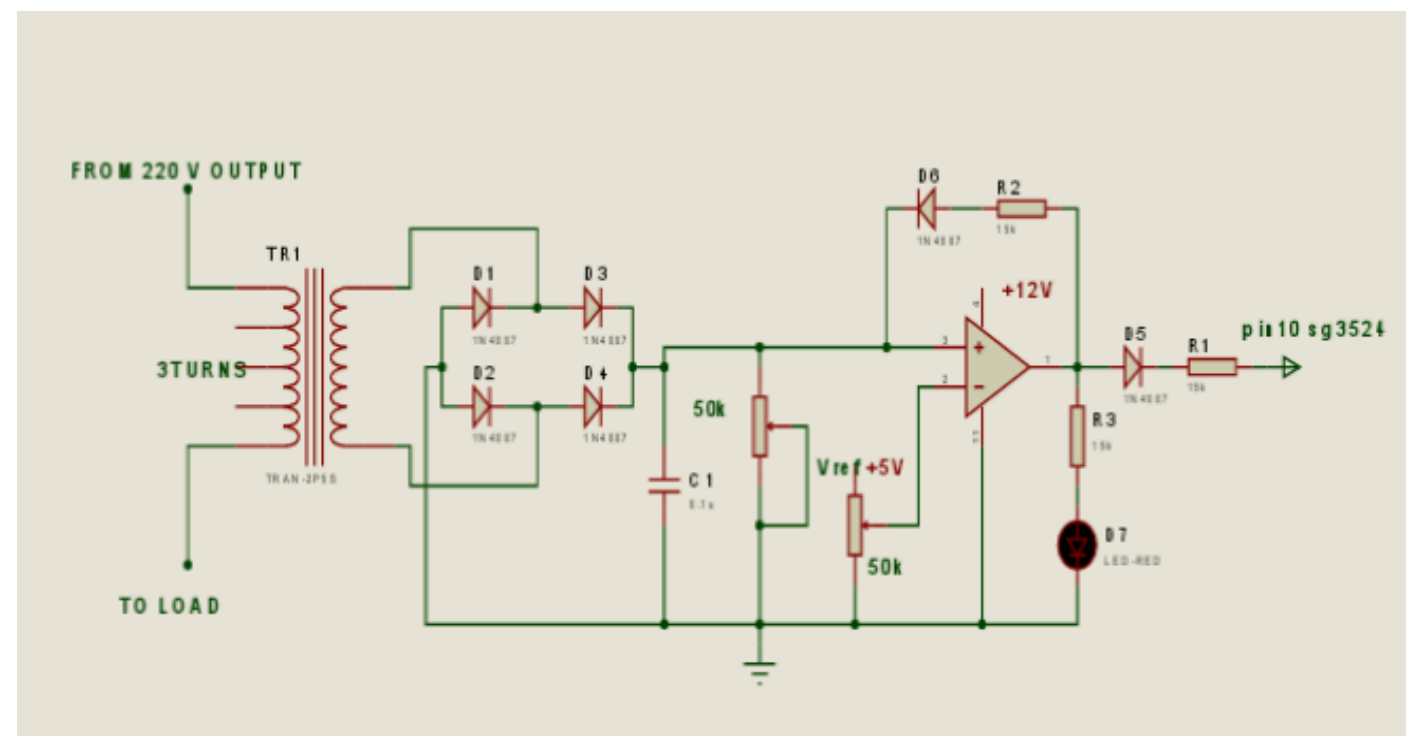

Fig 4 Schematic Diagram of Low Voltage Shut Down Circuitry.

The resistor (R1) and zener diode (D1) form voltage divider at non inverting terminal (pin3) of the comparator to provide reference voltage corresponding to the zener voltage (5volts) used the series resistor R4 controls the output gain of the comparator while the diode D4 prevents reverse voltage flow from pin3. Another potentiometet RV1 is provided at pin $\mathbf{2}$ of the comparator to monitor the battery voltage when drained to $\mathbf{2 1 . 5}$ volts. Its wiper (middle terminal) is connected to the pin 2 while the other two terminals is connected to both positive and negative terminals of the batteries to be monitored.

When ever the voltage level at pin2 is reduced below the reference voltage 5volts, the output of the comparator becomes HIGH (5volts or more) and the voltage at the same time flowing to the pin10 of SG3524 IC oscillator. The pin10 of the oscillator is an auto shut down pin in such that whenever it receives a positive voltage between $\mathbf{3 . 5}$ to $\mathbf{5}$ volts, it will inhibit the oscillator from pulsing. And once the power MOSFETs receive no signal from the oscillator, the whole system will be automatically shut down.

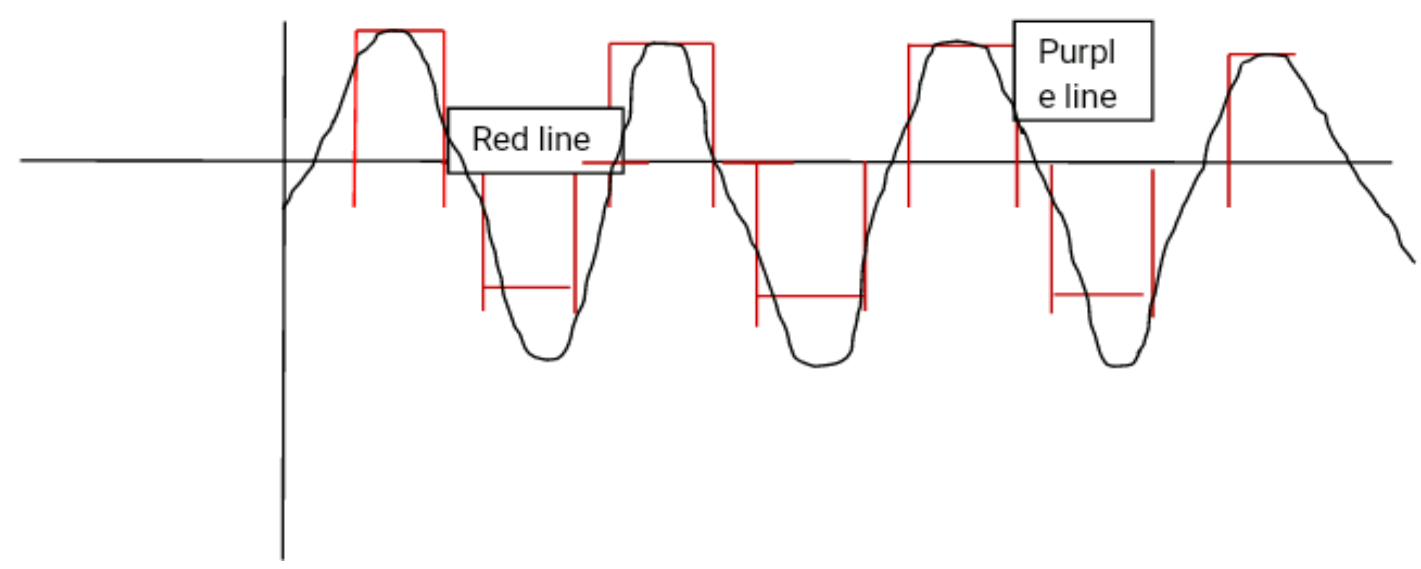

Fig 5 Schematic diagram of overload protection.

www.scirj.org 
The output of the low voltage small transformer (1000mA) was loose and it was re-wound with few turns (at least 3turns). The current flows through the few turn will be correspond to the induced voltage at the secondary side of the transformer. This voltage is an AC voltage which is rectified with the help of bridge diode and the filter capacitor (104) used. The pure DC voltage produced is fed to the non-inverting terminal (pin3) of the comparator while another potentiometer is connected to the inverting terminal in such that, its wiper is connected to the pin2 of the comparator to provide reference voltage. This was done in such that, whenever the current is high than the predetermined setting current (9Amp), the proportional voltage will be induced in the secondary winding then rectified and filter which will be high than inverting input voltage and as a result, the output of the comparator becomes HIGH as well. This will at same time flow to the pin10 of the oscillator to shut down the whole system.

The figure below shows the wave output of modified sine wave inverter. The inverter is made to produce an approximately sine wave with help of low pass filter used across the output of the power transformer. A high voltage low capacitance capacitor ( 0.1 IF/ 400volts) was used as a low pass filter. The red line shows the initial modified sine wave produced by the inverter while the purple line indicating the approximate sine wave produced when filtered.

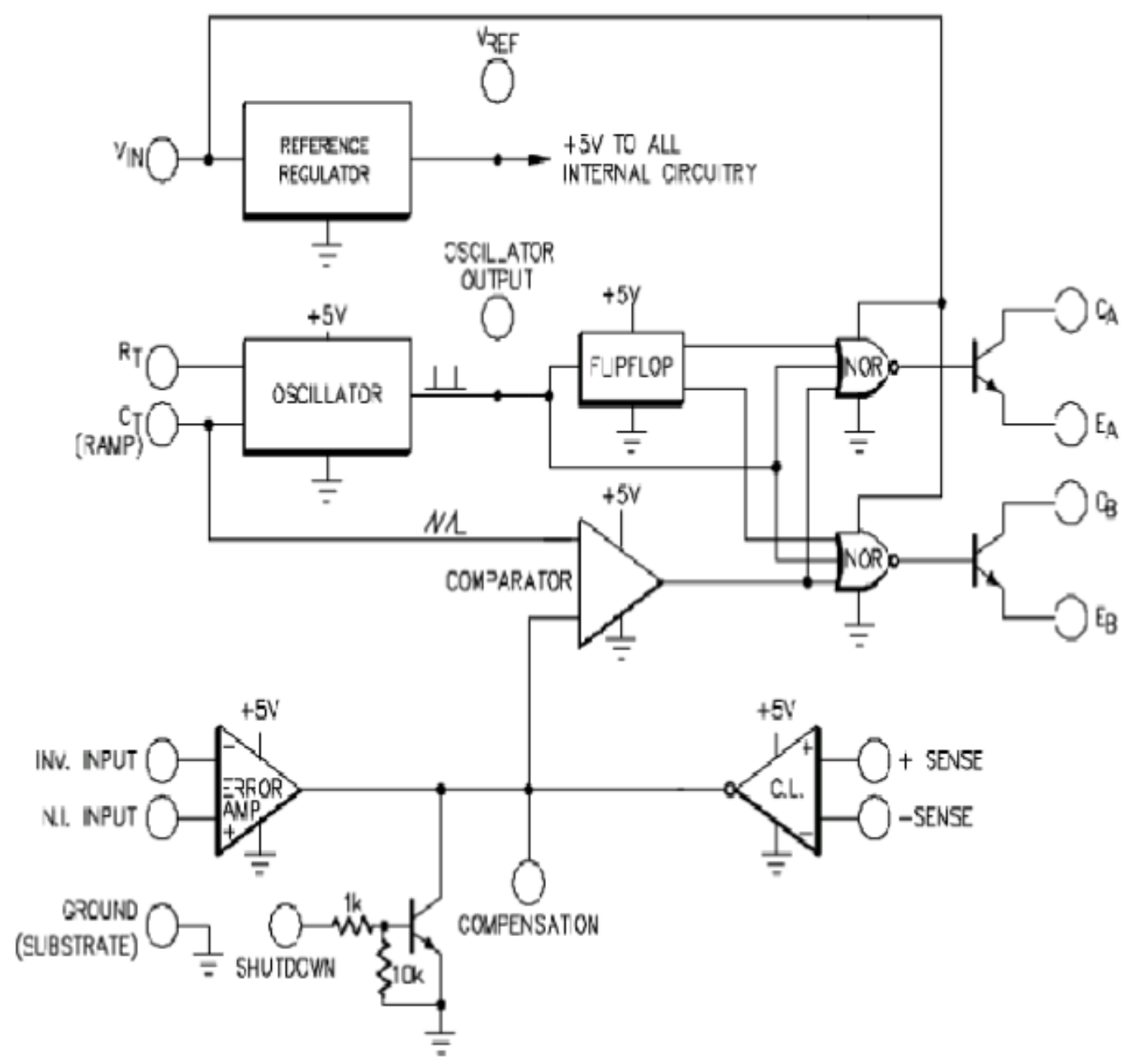

Fig 6

Shows wave output of PMW SG3524 inverter. 


\subsection{Internal Circuit Diagram of Oscillator Circuit SG3524IC.}

Below is a functional block diagram of oscillator SG3524. It displays all the internal components such as active and passive components fabricated in a single chip.

\subsection{Implementation and Testing.}

\subsection{Implementation}

The circuit of the whole diagram was constructed on the Vero board while the components were arranged and soldered on the Vero board as shown in the complete diagram. The following materials were used in packaging the inverter:

Fuses are used to protect the circuit (transformer and rectifying circuits) from flow of heavy current and high voltage which could be more than their ratings. Heat sink is used to remove the heat generated by the transistor to the surrounding air. A common 5Amp or $15 \mathrm{Amp}$ three pin power output socket is used in inverter to provide inverter output to the various devices. One can connect an ordinary 5/15Amp plug to the Inverter output.

\subsection{Testing}

After the necessary installation was completed the system was powered with printer, laptop, bulbs, sockets and desktop computer and observed for at least 10mins and were working properly.

\subsection{Maintenance}

The following maintenance procedures are outlined in order to ensure uninterrupted power supply

1. The right polarity of the Inverter battery terminals must be maintained on the battery that is, Red clip to positive terminal and Black clip to negative terminal.

2. Regular check-up of the battery electrolyte must be carried out. The electrolyte should be changed as soon as there is a change in colour.

3. A void bridging the .battery terminals for any reason.

\subsection{Conclusion and Recommendations}

\subsection{Conclusions}

A 1 KVA power inverter stand alone was designed to complement public power supply. Power inverter is a DC to AC inverter device that is capable of turning DC power in batteries or the one collected from solar panels into AC power that can run home appliances and electronics. The power inverter would transfer readily available DC power, from a battery or other stored power source, and turns it into readily usable AC power on available devices normally plug into a home electrical socket/ outlet. It will provide alternative energy for homes and offices. The solar panel employed receive solar energy from the sun and with battery. The inverter will convert the dc energy received from the sun to alternating voltage.

\subsection{Recommendation}

The power inverter will perform efficiently and can be safe on a plain, dry surface (indoors) and it must be kept away from hot weather and it should be placed within the close range of the battery supply to get a direct and clear signal. It will be good if the 
system is not overload with high power ratings equipment such as photocopy machine, air conditional should not be used when connect to solar source. Power inverters are not waterproof and should be kept from getting wet. It should be kept dry like any other electronics device. The inverter should not be allowed to get struck by lightning. Ensure that the power inverter is kept away from any kind of generated heat or flammable source that can cause overheating and fires. Higher rating can be developed, this will allow the students to carry out practicals and also solve the problem of incessant power supply and be fed into grid or use in companies and homes provided it is of high capacity.

\subsection{Reference}

[1] Abdullahi Babatunde Saka et al, "Solar Photovoltaic System: A case study of Akure, Nigeria", World Scientific News (WSN), Volume 83, No.6, 2017, Pp 15-28.

[2] https://en.m.wikipedia.org/wiki/solarcell

[3] Wael Charfi et al, " Performance Evaluation of a Solar Photovoltaic System", Energy Reports, Volume 4, No.2, 2018, Pp 400-406.

[4] Training Manual and Design on Maintenance of Uninterrupted Power Supply, 2013 "Embark Electronic" 